\title{
Geographic Information System enabled dengue surveillance system in south zone, Bangalore city: A pilot study
}

Naveen Ramesh ${ }^{1}$, Venkatesh Thimmaiah ${ }^{2}$, Shivkumar Mallaiah ${ }^{3}$, Anasuya Kandaswamy ${ }^{4}$

${ }^{1}$ Associate Professor, Department of Community Health, St. John's Medical College, Bangalore 560034. Karnataka. India; ${ }^{2}$ Program officer, Leprosy and NVBDCP, Bruhat Bengaluru Mahanagara Palike (BBMP), Government of Karnataka; ${ }^{3}$ Health Officer, South Bangalore, Bruhat Bengaluru Mahanagara Palike (BBMP), Government of Karnataka; ${ }^{4}$ Assistant Surgeon, Bruhat Bengaluru Mahanagara Palike (BBMP), Government of Karnataka

\begin{tabular}{|c|c|c|c|c|c|c|c|}
\hline Abstract & Introduction & Methodology & Results & Conclusion & References & Citation & $\underline{\text { Tables / Figures }}$ \\
\hline
\end{tabular}

\section{Corresponding Author}

Dr. Naveen Ramesh, Department of Community Health, St. John's Medical College, Bangalore 560034. India.

E Mail ID: drnaveenr@gmail.com

\section{Citation}

Ramesh N, Thimmaiah V, Mallaiah S, Kandaswamy A. Geographic Information System enabled dengue surveillance system in south zone, Bangalore city: A pilot study. Indian J Comm Health. 2021;33(1):153-160. https://doi.org/10.47203/IJCH.2021.v33i01.021

Source of Funding: Nil Conflict of Interest: None declared

\section{Article Cycle}

Received: 05/12/2020; Revision: 12/01/2021; Accepted: 05/02/2021; Published: 31/03/2021

This work is licensed under a Creative Commons Attribution 4.0 International License.

\section{Abstract}

Introduction: The Public Health Information and Epidemiological Cell (PHIEC) of Bruhat Bengaluru Mahanagara Palike (BBMP) utilizes the Geographic Information System (GIS) enabled integrated surveillance for collection, integration, analysis and reporting of geo-referenced epidemiological diseases in Bangalore city. Dengue fever is an emerging disease and there are minimum studies conducted in India about the GIS enabled dengue surveillance system. Objective: To assess the relationship between dengue cases and vector indices as depicted in the GIS map. Methodology: Data regarding dengue confirmed cases was obtained from PHIEC and entomological surveillance data from Urban Primary Health Centres (UPHC) for May to July 2017 in south zone of Bangalore city and active data collection was done for August and September 2017. Results: There was significant association between the number of dengue cases and the Breteau index in the month of September. However, there was no association between vector indices and the number of cases during the month of October. In some wards, contrary findings were noted between dengue vector indices and number of cases reported. Conclusion: There was a relationship between reported dengue cases and vector indices and there is a need for incorporation of entomological data into GIS system along with epidemiological and intervention data. Involvement of more private and government health care providers may help answer the gap between entomological data and number of dengue cases.

\section{Keywords}

Global Information System; Dengue; Surveillance; Vector Indices; Urban Area

\section{Introduction}

Dengue is an acute self-limiting viral disease and an emerging communicable diseases of public health importance commonly found in tropical and sub tropical regions. $(1,2)$
Dengue is mainly transmitted by female Aedes aegypti mosquito which rest in dark places within houses and breed in fresh artificial water.(3) In the recent past the incidence of dengue has increased globally mainly due to unplanned urbanization, increased international travel poor water 
management leading to increased potential mosquito breeding sites, and poor mosquito control measures in tropical countries. $(3,4)$

The incidence of dengue has increased by thirty-fold along with increased global geographic spread of the disease. More than $70 \%$ of the at-risk populations of dengue live in South East Asia and Western Pacific regions. $(2,5)$

In India, 35 states/Union Territories are endemic for dengue. In the year 2010, 28,292 cases and 110 deaths were reported and in 2013, there were 75,808 cases and 193 deaths.(3) In Karnataka, the number of confirmed cases and deaths have slowly increased over the years. From about 3,500 cases and two deaths in 2015 to about 6,000 cases and eight deaths in 2016.(6) Dengue, not only effect health but also imposes social and economic burden on the families of those affected in endemic areas.(2) At present, vector control is the main method of controlling and preventing transmission of dengue.(5) The public health system realized that timely information is required to prevent and control dengue.(7)

Geographic Information System (GIS) was used in prevention and control of dengue by capturing, storing, analyzing and displaying the data that are linked by common spatial coordinate system. Risk areas of dengue can be visualized instantly when areas of dengue are geographically mapped and also enables resource mobilization and to analyze the causes for dengue.(8)

In India, Bangalore is the fifth most populous city with an estimated population of 11.98 million and with the population density of 4381 persons per square kilometer. The rate of urbanization in Bangalore is three times faster when compared to all other states and $16 \%$ of the Karnataka state population resides in Bangalore.(9) (Figure 1).

Bruhat Bengaluru Mahanagara Palike (BBMP) is the administrative body responsible for the civic and infrastructural assets of Bangalore metropolitan area and is a single administrative unit consisting of wards, councils and few villages around the city. The BBMP include three major zones, south, west and east and five outer zones.

In the background of raising trend of both communicable and non-communicable diseases being the 'double burden of disease', rapid urbanization and increasing population in Bangalore city, a new unit called Public Health Information and Epidemiological Cell (PHIEC) was initiated by BBMP in January 2016, for better collection, integration, analysis and interpretation of geo-referenced data for both communicable and non-communicable diseases from all over Bangalore. The information would be received from both government and private hospitals including private practitioners, so that disease prone areas and vulnerable populations can be easily identified and mapped within Bangalore city using GIS. This information will also help deliver appropriate timely intervention and plan preventive measures. Dengue is one of the communicable diseases included in the list of 21 communicable diseases that would be reported to the PHIEC.

\section{Aims \& Objectives}

To explore the association between the number of confirmed dengue cases as mapped using GIS in PHIEC and the entomological surveillance data (dengue vector indices).

\section{Material \& Methods}

This was a cross sectional study done in the randomly selected areas in south zone of Bangalore. The south zone had five ranges, 44 wards and 162 health care facilities. (Figure 2)

Epidemiological data (reported cases of confirmed dengue) was collected from PHIEC and data related to entomological indicators was collected retrospectively for May to July 2017 and prospectively for August and September 2017 from Urban Primary Health Centers (UPHC) located in south Bangalore.

The epidemiological data included line listing of confirmed dengue cases, demographic details like patient's age, sex, address, hospital visit, laboratory method of diagnosis, etc.

The data regarding entomological indicators included, number of houses visited, number of containers inspected, number of houses found positive for the mosquito larvae, number of containers positive for the larvae, etc.

List of wards in the study area (south zone) were obtained from the BBMP office. Utilizing the list of wards available in the south zone, in view of feasibility of the study, ten wards were selected randomly by computer generated random number table. There were 541 confirmed dengue cases registered under PHIEC from May to October 2017 from these ten wards.

The study was done after obtaining ethical clearance from Institutional Ethics Committee, Rajiv Gandhi 
University of Health Sciences and required permissions was obtained from Commissioner of Health, BBMP and Medical Officer, BBMP.

The data collected was entered in MS Excel and analysed using SPSS version 16 .

The house-to-house entomological larval survey data were compiled and entomological indices house index (HI) percentage of houses infested with larvae and/or pupae, container index $(\mathrm{Cl})$ percentage of water-holding containers infested with larvae or pupae and Breteau index (BI) number of positive containers per 100 houses inspected were calculated.

\section{Results}

The study was conducted in south zone of the Bangalore city with the aim to explore the relationship between the epidemiological data of dengue from the PHIEC and the vector indices calculated from the surveillance data.

(Table 1), describes the age wise distribution of dengue confirmed cases in the study area i.e., south zone, Bangalore city from May to Oct 2017. There were total of 541 dengue confirmed cases reported to PHIEC during the study period. In our study, maximum number of cases was seen among adult in the age group 18 to 45 years and minimum cases in the age group zero to five years. Dengue cases were confirmed among extremes of age group, even among children less than 5 years $20(3.7 \%)$ of age and among elderly (above 60 years of age) 27 (5\%). The mean age of occurrence of dengue was 30 years and majority of the cases were males $309(57 \%)$.

The PHIEC received the epidemiological data (confirmed dengue cases both by Eliza NS1 and Eliza IgM) from the enrolled hospitals (private and public) on a weekly basis and the geographic location of cases were mapped in the system using GIS and were indicated as red colored lollypops (Figure 3 and 4). This information was shared with the concerned Medical Officers of Health $(\mathrm{MOH})$, Health Officers/epidemiologist, through auto generated email and SMS alerts for the necessary interventions. The information shared include the demographic details like sex, age, address, date of confirmation, hospital where confirmed, etc. $\mathrm{MOH}$ and team take up intervention and preventive actions which includes active house-to-house entomological survey and community awareness program in the form of Information Education and Communication (IEC). Entomological survey is conducted in atleast 50 houses surrounding the notified dengue case and activities undertaken during this survey includes source reduction-negating potential vector breeding sites, anti-larval and anti-adult measures. The IEC activities included education of the households, distributing of pamphlets, etc. about dengue symptoms and signs, modes of transmission, prevention including potential vector breeding sites. After the necessary actions were taken by $\mathrm{MOH}$, pictures of the actions taken were uploaded on to the system and the red colored lollypops turned into yellow colored lollypops. (Figure 3 ) and (Figure4)

During the study period, the number of reported dengue cases were less during the month of May (19) and maximum during the month of July (159) and almost equal number of cases in the months of August and September, 92 and 94 respectively. (Figure 5)

With respect to spread of dengue in south zone, maximum number of cases (231) is seen in Koramangala ward, followed by Sadguntepalya (146) and Ejipura (94). Minimum number of cases is observed in Bapujinagar (2) and Srinagar (2).

The (Table 2), describes the active entomological surveillance data i.e., house-to-house entomological survey, which included inspection of houses and surrounding areas for potential vector breeding sites and also documenting the number of houses and containers positive for mosquito larvae. Maximum number of houses and containers were positive in Lakkasandra ward and in the month of September.

(Table 3 ) given above shows dengue vector indices, $\mathrm{BI}, \mathrm{HI}, \mathrm{Cl}$, computed from the entomological surveillance data in each ward of the study area in south zone, Bangalore. In the study area, high BI $(>50)$, indicating high risk transmission was observed in Lakkasandra ward (71.5) and Koramangala (60) during the month of September. Low BI $(<5)$, indicating low risk transmission was seen in Jakkasandra (2.4) and Sadguntepalya (3.6) in the month of August. BI decreased during September in some of the wards like Kathriguppe, Vidyapeta and increased in all the other wards.

High $\mathrm{HI}(>10)$ was seen in wards like Kathriguppe, Vidyapeeta and Lakkasndra during the month of August and in most of the wards during September month.

$\mathrm{Cl}$ was observed to be higher in most of the study wards during the month of September.

(Table 4) compares the total number of dengue confirmed cases (reported to PHIEC) and vector 
indices like $\mathrm{BI}$ and $\mathrm{HI}$ of the respective wards of the study area in Bangalore city. It was observed that, there was a mismatch between the entomological indices and epidemiological data in all the wards both for the month of August and September 2017. Kormangala and Sudguntepalya and to some extent Ejipura reported higher number of confirmed cases and the entomological indices in all these three wards was also high for the month of August and September, 2017.

(Table 5 ) The above table shows correlation between numbers of dengue cases reported to PHIEC and vector indices like $\mathrm{BI}$ and $\mathrm{HI}$ computed from the entomological surveillance data during the months of August and September 2017. It was found that there was statistically significant correlation between the number of confirmed dengue cases and the Breteau Index during the month of September 2017. However, no significant correlation was found between the dengue confirmed cases and the vector indices for the month of August 2017.

\section{Discussion}

Dengue is an emerging infectious disease of public health importance and occurs mainly during the rainy season. BBMP planned to utilize GIS technology to improve the surveillance activities and to protect the health of residents of Bangalore.

PHIEC receives data about confirmed dengue cases both from public and private hospitals. This information is marked on the map of the respective zones of Bangalore and at present this information is not correlated with the entomological/vector indices of that zone.

This study found that PHIEC used the GIS to its advantage for localization of cases geographically and for taking interventions and preventive actions and this could be visualized in the map - red lollypops turning to yellow lollypops. The actions taken locally included minimum of 50 house-tohouse larval surveys to find the source or breeding places of the mosquito, anti-adult mosquito measures like fogging and IEC activities to educate people about protection against mosquito bites, about the disease, etc. Thus, GIS also helped monitor the control activities. This finding is similar to the study conducted in Mexico by Eugeno et. al. (7) where they integrated epidemiological, entomological data and control activities in the web enabled GIS in stepwise manner to identify and prioritize high risk areas and for better integrated dengue surveillance, decision making at all levels of public health system which helped in better management of dengue epidemics. Similar studies by Doncumbe et. al. (8) conclude that by using GIS technology it was possible to predict high risk areas and plan for control actions in future and also to mobilize scarce resources and thereby to reduce the burden of dengue. Another study by Gonzalex et. al., (10) in Venezuela showed that identifying dengue high risk area using GIS and understanding factors related to clustering of cases and how to manage dengue outbreak.

It was observed that most of the dengue cases, 385 (71\%) was seen among adults and among men $307(57 \%)$. This finding is similar to the study done by Prokopec et. al., (11) where they found a greater number of dengue cases among adult men.

It was observed that the number of dengue cases peaked in the month of July and lower number of cases was reported in the month of May 2017. These is because, the rainy seasons starts in May, peaks towards July and decrease by October in Bangalore. During the study period, it was observed more number of cases were reported from wards in BTM range like Koramangala, Sadguntepalya and Ejipura and minimum cases in other study wards which come under Vijaynagar range and Basavangudi range. The reason for this may be due to more number of 'slums' (A Slum, for the purpose of Census of India, has been defined as residential areas where dwellings are unfit for human habitation by reasons of dilapidation, overcrowding, faulty arrangements and design of such buildings, narrowness or faulty arrangement of street, lack of ventilation, light, or sanitation facilities or any combination of these factors which are detrimental to the safety and health) (12) in BTM range, with favor vector breeding.

\section{Entomological data}

As we could not get the data on dengue larval survey reports for the months of May-July, from the concerned UPHCs due to various reason, we could not calculate vector indices.

Active data collection was done for the months of August and September and it was found that the GIS data (number of dengue cases reported) was found to be associated with the Breteau index for the month of September 2017. Spearmen correlation coefficient analysis of vector indices and number of dengue cases revealed statistically significant association between the dengue cases and $\mathrm{BI}$ during 
the month of September. Higher the dengue cases, higher were the BI. However, this correlation was not significant during the month of August. It was observed that in some wards, high vector indices were not associated with higher number of dengue confirmed cases. The reasons could be due to less number of cases reported to PHIEC which depended on government and private health care facilities to report confirmed dengue cases - not all the private hospitals were enrolled in the PHIEC system, it was a recent initiative and only those cases confirmed by Eliza NS1 and Eliza IgM were included in the PHIEC data. The other reasons could be because people migrate to Bangalore from other places which could be endemic for dengue or residents could be bitten by the vector at their workplace, all this could have lead to mismatch between epidemiological and entomological data.

Similar observation was found in Thiruvananthapuram, India (13) where they found high vector indices and less dengue cases in some of their study regions and also in a study done by Parasuraman et.al. in Tamil Nadu (14) they found dengue outbreak in regions with low vector indices. Also, the data collected during entomological surveillance could be incorrect, because in the potential vector breeding sites are not only found in the house or its compound, it could also be in the surrounding environment of these residential areas like waste dumping areas/pits which were not included in calculating vector indices. This may also be due to missed/hidden vector breeding sites within the houses because not all the house and apartment complex allowed us to inspect the containers, hindering identification of exact vector breeding sites.

\section{Conclusion}

The study revealed that, there was significant correlation between the number of dengue cases reported to PHIEC and the Breteau Index for the month of September and there was no association with the House index. If all the health care professional both government and private were motivated to report all confirmed cases of dengue to PHIEC and if PHIEC could superimpose the entomological surveillance data into the GIS maps, it would help in better monitoring and surveillance of dengue.

Since PHIEC is a newer initiative by BBMP for surveillance of disease, further studies are required to monitor the epidemiological surveillance data which are backed by entomological surveillance data (for vector borne diseases) before scaling-up this activity in other parts of Bangalore and Karnataka.

\section{Recommendation}

Utilization of Geographic Information System (GIS) is of immense support and probably the way forward in maintaining health information of the communities both for communicable and noncommunicable diseases.

\section{Limitation of the study}

The study was of short duration and not all the required information was not available

\section{Relevance of the study}

State Governments are willing to adopt newer techniques for collecting health information and GIS will assist primary care doctors in tracking the real time health information and the impact of interventions.

\section{Authors Contribution}

NR, AK: Concept and design of study or acquisition of data or analysis and interpretation of data and Final approval of the version to be published. VT, SM: Acquisition of data and drafting the article for important intellectual content.

\section{Acknowledgement}

We thank all the Medical Officers of the participating Urban Primary Health Centers (UPHC), Bangalore.

\section{References}

1. Guidelines for prevention and control of Dengue. Zoonosis division, NICD and WHO; 2006. Available from: www.nvbdcp.gov.in. [Accessed 27 Feb 2021]

2. Dengue guidelines for diagnosis, treatment, prevention and control. WHO and TDR 2009. Available from http://whqlibdoc.who.int/publications/2009/9789241547 871 eng.pdf [Accessed 27 Feb 2021]

3. National vector borne disease control program (NVBDCP) 2015. Available from: http://nvbdcp.gov.in/den cd [Accessed 27 Feb 2021]

4. Chang AY, Parrales ME, Jimenez J, Sobieszczyk ME, Hammer SM, Copenhaver DJ, Kulkarni RP. Combining Google Earth and GIS mapping technologies in a dengue surveillance system for developing countries. Int J Health Geogr. 2009;8:49. doi: 10.1186/1476-072X-8-49. PMID: 19627614; PMCID: PMC2729741.[PubMed].

5. WHO Dengue and severe dengue. WHO. Available from: http://www.who.int/mediacentre/factsheets/fs117/en/ [Accessed 27 Feb 2021]

6. NVBDCP /Dengue/dhf situation in India. NVBDCP. Available from: http://www.nvbdcp.gov.in/den-cd [Accessed 27 Feb 2021] 
INDIAN JOURNAL OF COMMUNITY HEALTH / VOL 33 / ISSUE NO 01 / JAN- MAR 2021

7. Hernández-Ávila JE, Rodríguez MH, Santos-Luna R, SánchezCastañeda V, Román- Pérez S, Ríos-Salgado VH, SalasSarmiento JA. Nation-wide, web-based, geographic information system for the integrated surveillance and control of dengue fever in Mexico. PLoS One. 2013 ;8(8):e70231. doi: 10.1371/journal.pone.0070231. PMID: 23936394; PMCID: PMC3735575.[PubMed]

8. Duncombe J, Clements A, Hu W, Weinstein P, Ritchie S, Espino FE. Geographical information systems for dengue surveillance. Am J Trop Med Hyg. 2012;86(5):753-5. doi: 10.4269/ajtmh.2012.11-0650. PMID: 22556070; PMCID: PMC3335676.[PubMed]

9. India population 2017. Available from: http://www.indiapopulation2017.in/population-ofbengauru-017.html [Accessed 27 Feb 2021]

10. Vincenti-Gonzalez MF, Grillet ME, Velasco-Salas ZI, Lizarazo EF, Amarista MA, Sierra GM, Comach G, Tami A. Spatial Analysis of Dengue Seroprevalence and Modeling of Transmission Risk Factors in a Dengue Hyperendemic City of Venezuela. PLoS Negl Trop Dis. 2017;11(1):e0005317. doi: 10.1371/journal.pntd.0005317. PMID: 28114342; PMCID: PMC5289626.[PubMed]

11. Vazquez-Prokopec GM, Kitron U, Montgomery B, Horne P, Ritchie SA. Quantifying the spatial dimension of dengue
[GIS enabled dengue...] | Ramesh $\mathrm{N}$ et al virus epidemic spread within a tropical urban environment. PLoS Negl Trop Dis. 2010;4(12):e920. doi: 10.1371/journal.pntd.0000920. PMID: 21200419; PMCID: PMC3006131. [PubMed].

12. Primary Census Abstract for Slum. Census of India 2011. Office of the Registrar General and Census Commissioner, India New Delhi. Available from http://www.censusindia.gov.in/2011-Documents/Slum-2609-13.pdf [Accessed 27 Feb 2021]

13. Basker P, Kolandaswamy KG. Study on the Behavior of Dengue Viruses during Outbreaks with Reference to Entomological and Laboratory Surveillance in the Cuddalore, Nagapattinam, and Tirunelveli Districts of Tamil Nadu, India. Osong Public Health Res Perspect. 2015;6(3):143-58. doi: 10.1016/j.phrp.2015.05.001. Epub 2015 May 21. PMID: 27606255; PMCID: PMC4986583.[PubMed].

14. Vijayakumar K, Sudheesh Kumar TK, Nujum ZT, Umarul F, Kuriakose A. A study on container breeding mosquitoes with special reference to Aedes (Stegomyia) aegypti and Aedes albopictus in Thiruvananthapuram district, India. J Vector Borne Dis. 2014;51(1):27-32. PMID: 24717199. [PubMed].

\section{Tables}

\section{TABLE 1 AGE WISE DISTRIBUTION OF DENGUE CASES}

\begin{tabular}{|l|l|l|}
\hline Age group (in years) & Confirmed Dengue cases $(\mathbf{n})$ & Dengue cases $(\%)$ \\
\hline $0-5$ & 20 & 3.7 \\
\hline$>5-18$ & 54 & 10 \\
\hline$>18-45$ & 385 & 71.1 \\
\hline$>45-60$ & 55 & 10.2 \\
\hline$>60$ & 27 & 5 \\
\hline TOTAL & 541 & 100 \\
\hline
\end{tabular}

TABLE 2 ENTOMOLOGICAL SURVEILLANCE DATA OF THE SOUTH ZONE WARDS, BANGALORE

\begin{tabular}{|c|c|c|c|c|c|c|c|c|}
\hline \multirow[t]{2}{*}{ WARDS } & \multicolumn{4}{|c|}{ AUGUST } & \multicolumn{4}{|c|}{ SEPTEMBER } \\
\hline & THI & TH+ & $\mathrm{TCl}$ & $\mathrm{TC}+$ & THI & $\mathrm{TH}+$ & $\mathrm{TCl}$ & TC+ \\
\hline Kathriguppe & 310 & 40 & 1049 & 65 & 660 & 48 & 2500 & 72 \\
\hline Vidyapeeta & 371 & 47 & 1712 & 61 & 659 & 55 & 4000 & 92 \\
\hline Ejipura & 335 & 30 & 735 & 44 & 609 & 76 & 1445 & 90 \\
\hline Jakkasandra & 332 & 8 & 2360 & 8 & 400 & 100 & 746 & 18 \\
\hline Lakkasandra & 840 & 229 & 4423 & 406 & 974 & 357 & 4241 & 696 \\
\hline Koramangala & 230 & 20 & 450 & 30 & 450 & 80 & 1900 & 27 \\
\hline Sadguntepalya & 387 & 10 & 1358 & 14 & 660 & 100 & 1950 & 26 \\
\hline Bapujinagar & 288 & 18 & 492 & 22 & 723 & 71 & 2986 & 97 \\
\hline Vijaynagar & 230 & 20 & 298 & 25 & 600 & 55 & 1500 & 68 \\
\hline
\end{tabular}

TABLE 3 DENGUE VECTOR INDICES OF VARIOUS WARDS OF SOUTH ZONE, BANGALORE

\begin{tabular}{|l|r|r|r|r|r|r|r|r|}
\hline & \multicolumn{3}{|c|}{ AUGUST } & \multicolumn{5}{c|}{ SEPTEMBER } \\
\hline Kathriguppe & BI & & HI & Cl & BI & HI & Cl \\
\hline Vidyapeeta & & 20.9 & 12.9 & 6.2 & 10.9 & 7.3 & 2.9 \\
\hline Ejipura & 16.4 & 12.7 & 3.6 & 14 & 8.3 & 2.3 \\
\hline Jakkasandra & 13.1 & 9 & 6 & 14.8 & 12.5 & 6.2 \\
\hline
\end{tabular}


INDIAN JOURNAL OF COMMUNITY HEALTH / VOL 33 / ISSUE NO 01 / JAN- MAR 2021

[GIS enabled dengue...] | Ramesh $\mathrm{N}$ et al

\begin{tabular}{|l|r|r|r|r|r|r|}
\hline Lakkasandra & 48 & 27.3 & 9.2 & 71.5 & 36.7 & 16.4 \\
\hline Koramangala & 13 & 8.7 & 6.7 & 60 & 17.8 & 14.2 \\
\hline Sadguntepalya & 3.6 & 2.6 & 1 & 39.4 & 15.2 & 13.3 \\
\hline Bapujinagar & 7.6 & 6.3 & 4.5 & 13.4 & 9.8 & 3.2 \\
\hline Vijaynagar & 11 & 8.7 & 8.4 & 11.3 & 9.2 & 4.5 \\
\hline
\end{tabular}

NOTE: $\mathrm{BI}=$ Breteau Index $\mathrm{HI}=$ House Index, $\mathrm{Cl}=$ Container index

\begin{tabular}{|l|l|l|l|l|l|l|}
\hline $\begin{array}{l}\text { TABLE 4 DENGUE CASES AND VECTOR INDICES IN VARIOUS WARDS OF SOUTH ZONE, BANGALORE } \\
\text { WARDS }\end{array}$ & $\begin{array}{l}\text { AUGUST } \\
\text { Nengue cases* }\end{array}$ & HI & BI & Dengue cases* & HI & BI \\
\hline Kathriguppe & 0 & 12.9 & 20.9 & 0 & 7.3 & 10.9 \\
\hline Vidyapeeta & 0 & 12.7 & 16.4 & 1 & 8.3 & 14 \\
\hline Ejipura & 21 & 9.0 & 13.1 & 15 & 12.5 & 14.7 \\
\hline Jakkasandra & 5 & 2.4 & 2.4 & 1 & 25.0 & 45 \\
\hline Lakkasandra & 4 & 27.3 & 48 & 6 & 36.7 & 71 \\
\hline Koramangala & 43 & 8.7 & 13 & 40 & 17.8 & 60 \\
\hline Sadguntepalya & 17 & 2.6 & 3.6 & 37 & 15.2 & 39.4 \\
\hline Bapujinagar & 0 & 6.3 & 7.6 & 0 & 9.8 & 13.4 \\
\hline Vijaynagar & 1 & 8.7 & 11 & 0 & 9.2 & 11.3 \\
\hline Note: * *onfirmed dengue cases, HI - House Index, BI - Breteau Index & & & \\
\hline
\end{tabular}

TABLE 5 CORRELATION BETWEEN NUMBER OF DENGUE CASES AND DENGUE VECTOR INDICES

\begin{tabular}{|l|l|l|l|l|}
\hline \multicolumn{1}{|c}{ Vector Indices } & August & September \\
\hline Spearmen Correlation coefficient value & BI & HI & BI & HI \\
\hline P value & -0.25 & -0.298 & 0.775 & 0.613 \\
\hline *Statistically significant & 0.509 & 0.436 & $0.014^{*}$ & 0.079 \\
\hline
\end{tabular}

\section{Figures}

\section{FIGURE 1 AREA MAP OF BANGALORE CITY}

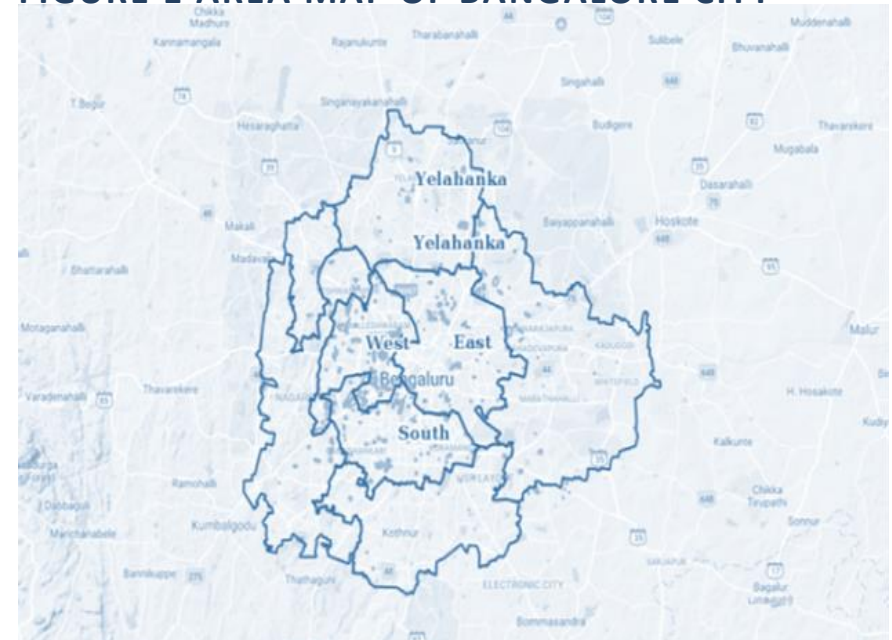

Source: $P H I E C, B B M P$.

Note: BBMP consists of total eight zones, three major zones, south, east, west and five outer zones such as Yelahanka, Rajarajeshwari Nagar, Bommanahalli, Mahadevpura and Dasarahalli with separate administration and 198 wards.
FIGURE 2 AREA MAP OF SOUTH ZONE,

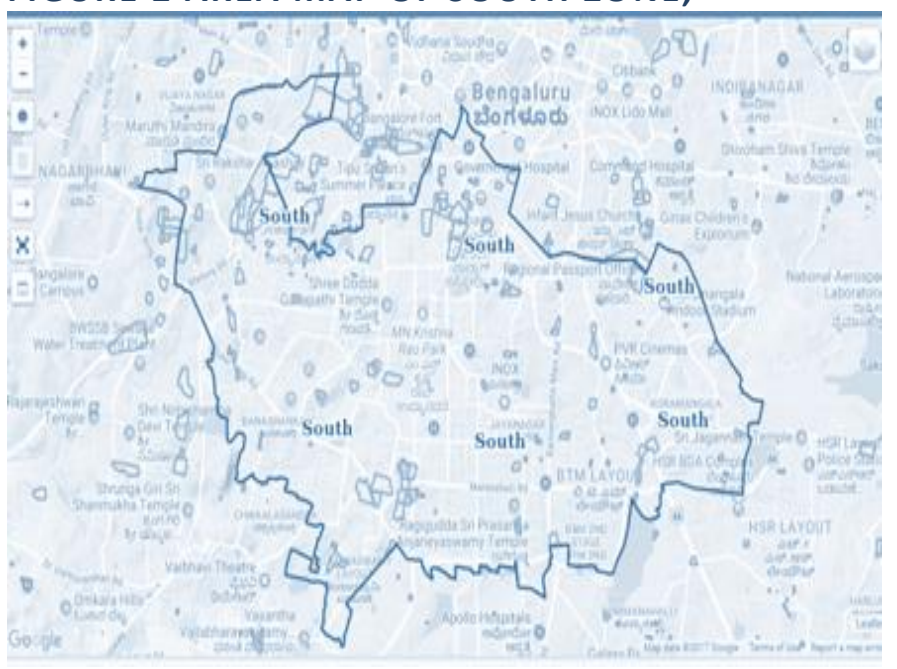

Soure: PHIEC, BBMP

Note: Green colored area depicts 'slums. South zone has total of 44 wards with population of 17 lakhs and 162 Health care facilities, which includes 37 Urban Primary Health Centers and 25 Private Health Care facilities. 


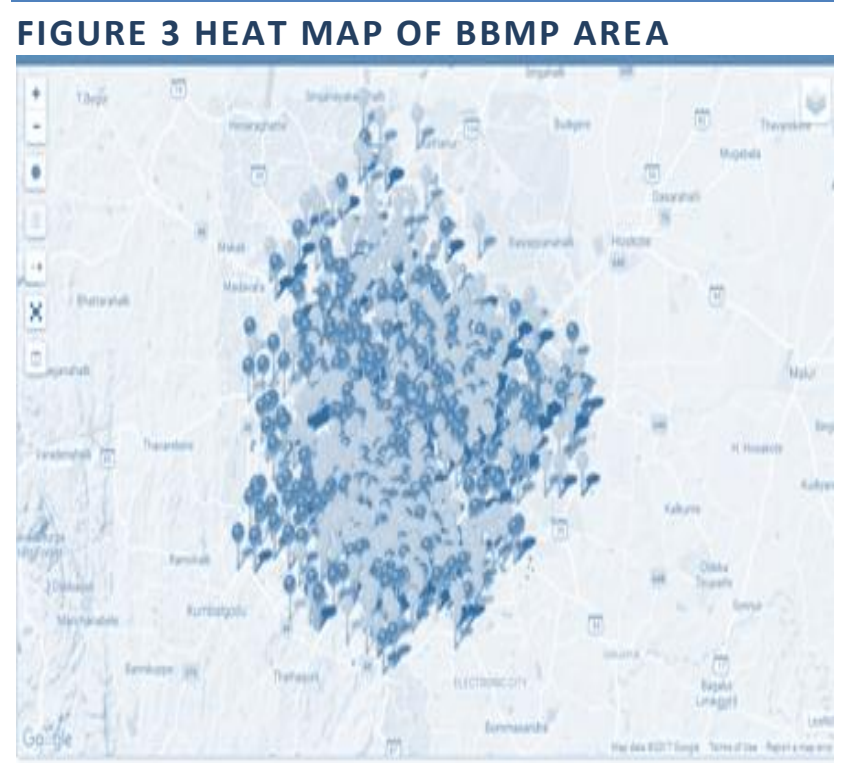

Source: $P H I E C, B B M P$

Note: Red colored lollypops indicate dengue confirmed cases and the yellow color indicates interventions/actions taken after each case reported to the concerned medical officers. PHIEC has 581 reporting units till date, out of 153 units report regularly.
FIGURE 4 HEAT MAP OF SOUTH ZONE SHOWING DENGUE CASES AND ACTIONS TAKEN

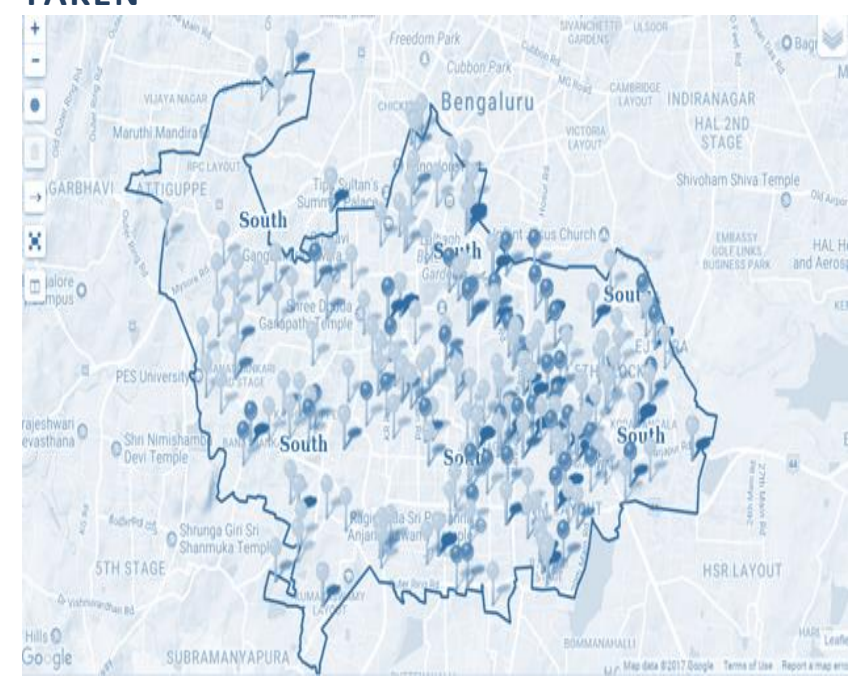

Source: PHIEC, BBMP

Note: Red colored lollypops indicate dengue confirmed cases and yellow colored lollypops indicate actions taken.

\section{FIGURE 5 MONTH WISE DISTRIBUTION OF DENGUE CASES}

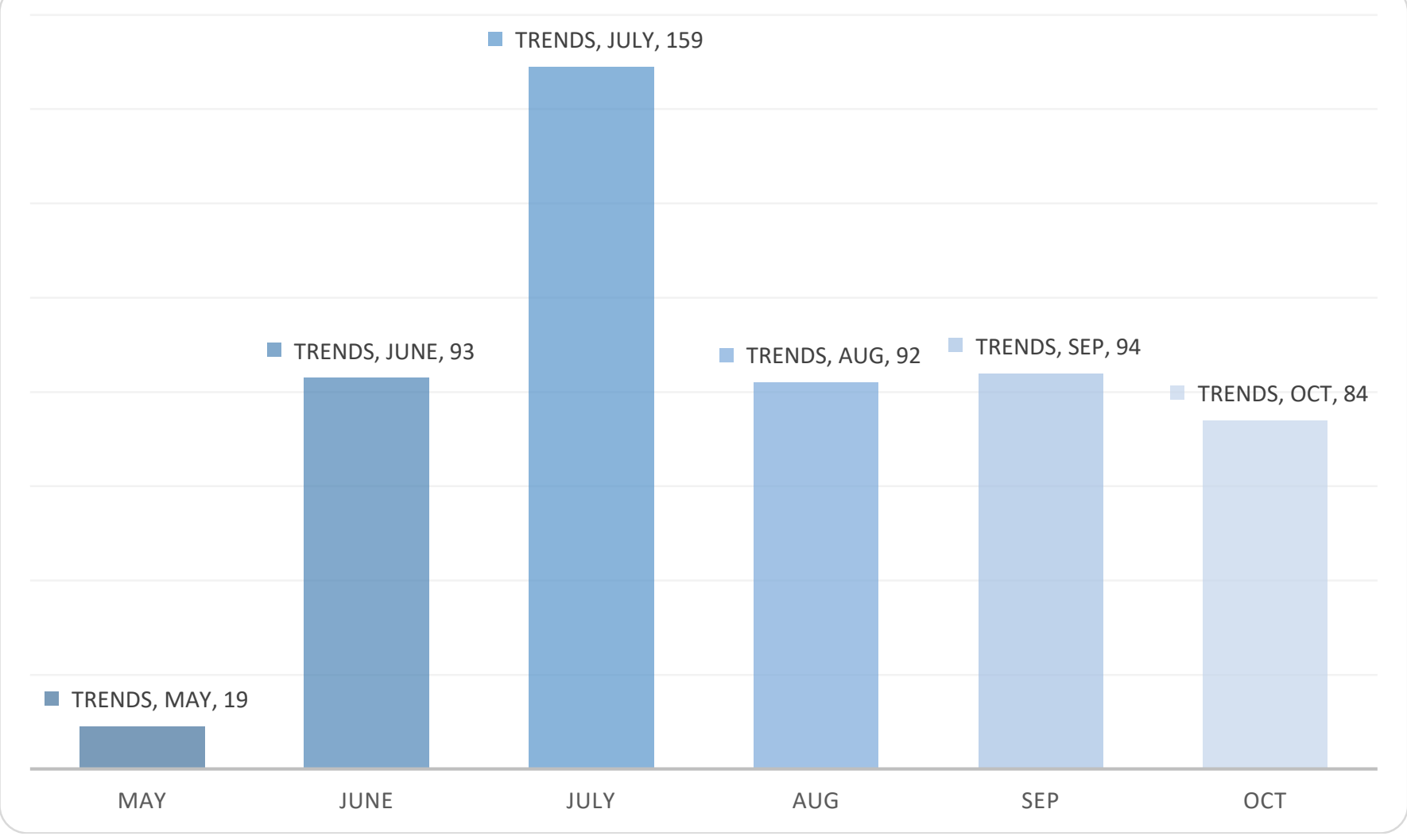

